University of Nebraska - Lincoln

DigitalCommons@University of Nebraska - Lincoln

Faculty Papers and Publications in Animal

Science

Animal Science Department

1998

\title{
Evaluation of the Ovine Callipyge Locus: I. Relative Chromosomal Position and Gene Action
}

\author{
B. A. Freking \\ U.S. Meat Animal Research Center, Clay Center, NE, brad.freking@ars.usda.gov \\ J. W. Keele \\ Roman L. Hruska U.S. Meat Animal Research Center, USDA-ARS, Clay Center, NE \\ C. W. Beattie \\ Roman L. Hruska U.S. Meat Animal Research Center, USDA-ARS, Clay Center, NE \\ S. M. Kappes \\ Roman L. Hruska U.S. Meat Animal Research Center, USDA-ARS, Clay Center, NE \\ T. P.L. Smith \\ U.S. Meat Animal Research Center, tim.smith@ars.usda.gov
}

See next page for additional authors

Follow this and additional works at: https://digitalcommons.unl.edu/animalscifacpub

Part of the Animal Sciences Commons

Freking, B. A.; Keele, J. W.; Beattie, C. W.; Kappes, S. M.; Smith, T. P.L.; Sonstegard, T. S.; Nielsen, Merlyn K.; and Leymaster, Kreg A., "Evaluation of the Ovine Callipyge Locus: I. Relative Chromosomal Position and Gene Action" (1998). Faculty Papers and Publications in Animal Science. 500.

https://digitalcommons.unl.edu/animalscifacpub/500

This Article is brought to you for free and open access by the Animal Science Department at DigitalCommons@University of Nebraska - Lincoln. It has been accepted for inclusion in Faculty Papers and Publications in Animal Science by an authorized administrator of DigitalCommons@University of Nebraska Lincoln. 


\section{Authors}

B. A. Freking, J. W. Keele, C. W. Beattie, S. M. Kappes, T. P.L. Smith, T. S. Sonstegard, Merlyn K. Nielsen, and Kreg A. Leymaster 


\section{Evaluation of the Ovine Callipyge Locus: I. Relative Chromosomal Position and Gene Action ${ }^{1,2,3}$}

\section{B. A. Freking*,t,4, J. W. Keele*, C. W. Beattie*,5, S. M. Kappes*, T.P.L. Smith*, T. S. Sonstegard*,6, M. K. Nielsent, and K. A. Leymaster*,7}

*Roman L. Hruska U.S. Meat Animal Research Center, ARS, USDA, Clay Center, NE 68933 and tDepartment of Animal Science, University of Nebraska-Lincoln 68583-0908

\begin{abstract}
Genotypic and phenotypic data were collected to estimate chromosomal position of the callipyge (CLPG) gene and to test gene action. Nine Dorset rams of extreme muscling phenotype and 114 Romanov ewes composed the grandparent generation of a resource flock of $362 \mathrm{~F}_{2}$ lambs segregating at the CLPG locus. The parent generation consisted of eight $\mathrm{F}_{1}$ sires and $138 \mathrm{~F}_{1}$ dams. The $\mathrm{F}_{2}$ lambs were serially slaughtered in six groups at 3-wk intervals starting at 23 wk of age to allow comparisons at different end points. A linkage group of 25 marker loci (mean of 708 informative meioses per marker) spanning $87.2 \mathrm{cM}$ was developed and improved the previous known coverage and precision of marker order and interval distance from available maps of ovine chromosome 18. Probabilities of each CLPG genotype were calculated at 1 -cM intervals ( 0 to $107 \mathrm{cM}$ ). Statistical models included effects of year, sex, sire, regressions on genotypic probabilities, and genotype-specific linear
\end{abstract}

and quadratic regressions on appropriate covariates. Orthogonal contrasts of CLPG genotypic effects evaluated additive, maternal dominance, and paternally derived polar overdominance models of gene action. The most parsimonious model did not include the additive and maternal dominance genetic contrasts. From analyses of four key traits, a consensus for position of CLPG was obtained at $86 \mathrm{cM}$ relative to the most centromeric marker. An F-test with 3 df representing polar overdominance was maximum at position $86 \mathrm{cM}(\mathrm{F}=407.4$; $\mathrm{P}<.00001)$ with leg score as the dependent variable. These results are consistent with assignment of the CLPG locus to the telomeric region of chromosome 18 and support the polar overdominance model of gene action proposed by Cockett et al. (1996). Furthermore, recombinant individuals with definitive phenotypes confined the position of CLPG to a 3.9-CM interval, facilitating positional cloning experiments.

Key Words: Callipyge, Sheep, Carcass Composition, Genes

\section{Introduction}

\footnotetext{
${ }^{1}$ We acknowledge contributions by Noelle Cockett, Biotechnology Center, Utah State Univ., for supplying redesigned primer pair information for a bovine microsatellite; Heather Burkin of AgResearch, Molecular Biology Unit, Univ. of Otago, New Zealand, for screening of the ovine YAC library; and Steven Shackelford, Meats Research Unit, U.S. Meat Animal Research Center, for assignment of leg muscling scores to carcasses.

${ }^{2}$ Mention of a trade name, proprietary product, or specific equipment does not constitute a guarantee or warranty by the USDA and does not imply approval to the exclusion of other products that may be suitable.

${ }^{3}$ Published as paper no. 12074, J ournal Ser., Nebraska Agric. Res. Div., Univ. of Nebraska, Lincoln 68583-0908.

${ }^{4}$ Partly supported by the Center for Biotechnology, Univ. of Nebraska-Lincoln and the American Sheep Industry National Wool Growers Memorial Fellowship.

${ }^{5}$ Current address: Univ. of Minnesota, Dept. of Vet. Pathobiol., Coll. of Vet. Med., St. Paul, MN 55108.

${ }^{6}$ Current address: USDA, ARS, Gene Evaluation and Mapping Lab, Livestock \& Poultry Sci. Inst., BARC-East, Bldg. 200, Room 101B, Beltsville, MD 20705.

${ }^{7}$ To whom correspondence should be addressed: P.O. Box 166.
}

A Dorset ram born in 1983 in the Moffat flock near Piedmondt, OK, conferred postnatal development of an extreme, heavy-muscled phenotype to some of his descendants. Phenotypic ratios of progeny derived from designed matings were consistent with a new mutant allele with nonrecessive gene action at a single, autosomal locus (J ackson et al., 1997). The locus, designated callipyge (CLPG), mapped to the telomeric region of ovine chromosome 18 (Cockett et al., 1994). The gene action of CLPG was further elucidated by Cockett et al. (1996) based on limited numbers of offspring from five different mating combinations, where the maternal and paternal alleles were inferred from five DNA markers on chromosome

Received October 27, 1997.

Accepted April 8, 1998. 
18. The term polar overdominance was used to describe the genetic model in which only heterozygous individuals that were receiving the newly identified allele from their sire expressed the unique phenotype.

Callipyge phenotypic effects were previously estimated from data collected on heterozygous (mutant CLPG allele inherited from the sire) and noncarrier lambs, with each lamb subjectively classified as expressing either the callipyge or normal phenotype. Experiments used relatively few animals, and the lambs were typically slaughtered at similar ages or live weights, which limited statistical inference. Estimates of effects of all four CLPG genotypes, with inferences over wide ranges of biological and economical end points, are needed to provide complete information to sheep industries in the United States and abroad. The objectives for this experiment were to increase marker density on ovine chromosome 18, to refine the chromosomal position of CLPG, and to test different models of gene action; this information is prerequisite for precise estimation of CLPG genotypic effects.

\section{Materials and Methods}

\section{Population Structure}

Nine rams of the Dorset breed were identified based on visual appraisal of muscle mass and pedigree relationships that traced back within four generations to the presumed founder ram (Solid Gold) from the Moffat flock. Romanov ewes ( $n=255)$, assumed to be noncarriers of the mutant allele, were exposed to the nine Dorset rams in single-sire mating pens during two distinct 35-d breeding seasons in the fall of 1992. Each $F_{1}$ lamb was subjectively classified as expressing either the callipyge or the normal phenotype at 4, 8, and 12 wk of age; results demonstrated that each Dorset sire was heterozygous at the CLPG locus. All healthy dam-reared $F_{1}$ ewe lambs, regardless of phenotype, from the first lambing group were retained for breeding $(n=105)$. The $F_{1}$ ewe lambs that expressed the callipyge phenotype were preferentially selected from the second lambing group, resulting in an additional 47 ewe lambs available for breeding in 1993. Two-thirds of the $152 F_{1}$ ewe lambs were evaluated as callipyge phenotype, and the remaining one-third was classified as normal phenotype. Therefore, the frequency of the mutant CLPG allele in these ewe lambs was approximately .33. Eight $F_{1}$ ram lambs evaluated as exhibiting the callipyge phenotype were used as sires of the next generation. Two replicates of $F_{2}$ lambs $(n=432)$ were born to $138 F_{1}$ ewes during 1994 and 1995. Three of the $F_{1}$ sires were used during both years of matings. One $F_{1}$ sire used only in the second year was ultimately shown to not carry the mutant allele, and it thus produced no detectable informative meioses for the CLPG locus.

\section{Phenotypic Data Collection}

Routine data collected on individuals included date of birth, sex, lambing difficulty, date and cause of mortality, type of birth-rearing, defects, and weights recorded at birth and at 8 (weaning), 14, and $20 \mathrm{wk}$ of age. Ranges in lambing dates were 37 and $38 \mathrm{~d}$ for each year of $F_{2}$ lamb production, and the appropriate data were recorded when a contemporary weaning group averaged the target age. Ram lambs were castrated shortly after birth, and lambs unable to be naturally reared were slaughtered. Following weaning, lambs were allowed ad libitum access to standard diets in a feedlot setting.

The $F_{2}$ ewe and wether lambs were serially slaughtered at 23, 26, 29, 32, 35, and 38 wk of age ( $n$ = approximately 30 per age group per year). Live weight was recorded the morning of slaughter on lambs given continual ad libitum access to feed and water. Pelt (including feet), kidney-pelvic fat, liver, and hot carcass weights were measured. Ovaries of ewe lambs were examined for pubertal status and number of corpora lutea. Following a 24-h chill, carcass weight was again recorded and width of the carcass recorded at the widest points of the shoulder and rump using callipers. A subjective leg muscling score, normally scaled from 1 (low cull) to 15 (high prime), was assigned to each of the carcasses after sorting them on the rail from heaviest- to lightestmuscled. In this sample, scores varied from 9 to 17 because some carcasses exhibited degrees of muscling beyond the high prime classification. Carcasses were split along the dorsal midline, and the right-side weight was recorded. Carcass length was measured from the anterior edge of the first rib to the anterior edge of the aitch bone. Metacarpal bone length was measured. Fat depths were recorded at two locations: at the midpoint over the longissimus muscle between the 12th and 13th ribs and at the midline of the fourth sacral vertebra.

To evaluate distributions of carcass components, the right side was cut into three sections: anterior (shoulder, neck, foreshank, and breast), midsection (loin, rib, and flank), and posterior (sirloin, leg, and hindshank). Each section was weighed separately. The anterior section and midsection were separated between the fifth and sixth ribs. The posterior section was separated from the midsection between the second-to-last and last lumbar vertebrae. The midsection was split between the 12th and 13th ribs, where depth, width, surface area, and subjective marbling score $(0=$ devoid; $200=$ traces; $400=$ small; $600=$ moderate) were evaluated at the surface of the longissimus muscle. Complete sections were frozen and subsequently ground separately to determine chemical composition by proximate analysis of water, protein, ether extract, and ash components. Weight of fat-free lean or other components on a whole carcass basis were derived from the sums of the three sections. 


\section{Genotypic Data Collection}

Forty-four primer pairs from 42 distinct loci previously mapped to either ovine chromosome 18 or the homologous bovine chromosome 21 were evaluated in this population. Information on the 25 useful markers in this population is summarized in Table 1 . One locus was a polymorphism of restriction sites for the enzyme $\mathrm{Mspl}$ in an amplified region of the IGF-1R locus initially described by Moody et al. (1996) as a Taql bovine polymorphism. The allele products for this locus were resolved by electrophoresis of digested samples on a $3 \%$ agarose gel and visualized by UV light following ethidium bromide staining. Primers designed around microsatellite sequences from either bovine or ovine species were used at remaining loci.

The lack of highly informative microsatellite primer pairs near the telomeric region of ovine chromosome 18 prompted isolation of additional microsatellite loci using available markers and an ovine yeast artificial chromosome (YAC) library (Broom and Hill, 1994). The primer pair for the BMS1561 marker was used to screen the library and isolate two unique YAC clones containing this locus. Two microsatellite markers (OY 3, OY 5) were subsequently developed from one of the YAC clones using the procedures of Sonstegard et al. (1998). This clone has been physically assigned by fluorescence in situ hybridization to ovine chromosome 18 and is near but not at the telomere (unpublished data) with no evidence of chimerism.

Microsatellite loci were amplified by PCR with direct incorporation of $[\alpha-32 \mathrm{P}] \mathrm{dATP}$ using standard protocols (de Gortari et al., 1997). Three microsatellite loci (CSSM 18, TGLA122, OARVH54) were alternatively end-labeled [ $\left.\gamma^{-32} \mathrm{P}\right]$ using a kinase reaction with the forward primer to reduce sub-banding and enhance accuracy of scoring these loci. Standard protocols for thermal cycling and electrophoresis conditions have been reported (Bishop et al., 1994; de Gortari et al., 1997).

Genotypes were independently scored twice using an entry screen system similar to that described by Rohrer et al. (1994) and entered into the USDAMARC relational database (Keele et al., 1994) from which data could be easily retrieved for linkage analyses. After several loci had been genotyped, it became apparent that several pedigree and(or) DNA source errors existed. This occurrence was anticipated given the high reproductive rates of the Romanov and $\mathrm{F}_{1}$ ewes and the penning protocols during the time of lambing; natural cross-fostering events could not be prevented. Six (4\%) $F_{1}$ ewes and $34(8 \%) F_{2}$ lambs had genotypes not possible given the parental information observed. Extraction of DNA from a different tissue source was conducted for these individuals and pedigree/DNA source errors were corrected when possible. Genotypes from two X-linked microsatellites were used to assist correct parentage identification.
Information from six $\mathrm{F}_{2}$ lambs was excluded from the final analysis because parentage could not be determined from currently available data.

\section{Linkage Group Analyses}

Linkage analyses were performed using CRI-MAP Version 2.4 software (Green et al., 1990). Initially, two-point logarithm of odds (LOD) tables were computed for all pairs of loci. The phase-unknown likelihood tolerance value, to test the null hypothesis of independent segregation, was set at a LOD of 3.0, and recombination rates were assumed equal in the two sexes. A total of 25 loci exceeded these minimum criteria for linkage and were subjected to multiple point analyses.

The BUILD option was used to construct the initial linear locus order. The tolerance levels used to discard alternative locus orders were set at highly stringent levels (LOD of 5.0) for phase known and phase unknown data. The remaining loci were placed into the linkage group by order of informative meioses using the ALL option with a lower tolerance level (LOD of 3.0) for rejection of locus orders. The FLIPS(n) option was used throughout the process of building the linkage group to evaluate all permutations of $\mathrm{n}$ consecutively ordered loci relative to the current reference order ( $\mathrm{n}$ varied from 2 to 5 ). The CHROMPIC option was used to identify unlikely crossover events not substantiated by changes in phase of adjacent loci regardless of genetic distance. The genotypes contributing to these events were amplified and scored a second time to resolve discrepancies and errors in interpretation. This is the process suggested by Buetow (1991) and, it proved valuable in identifying genotypic errors.

\section{Genotypic Probabilities}

A FORTRAN program was written to calculate conditional probabilities and analyses of variance to predict the position and test gene action of CLPG. An approach described by Haley et al. (1994) was implemented to evaluate evidence for the presence of the CLPG locus at sequential positions along the chromosome 18 linkage group. The display of grandparental origins of alleles generated by CHROMPIC for each chromosome 18 gamete in the $F_{2}$ generation with the phase choice having the highest likelihood was used to calculate conditional probabilities for each animal for each genotypic class at the CLPG locus. Conditional probabilities for the presence of the mutant CLPG allele (C) were determined on each gamete contributing to an $\mathrm{F}_{2}$ individual at $1-\mathrm{CM}$ intervals in the linkage group as a function of the recombination rates with the two informative, flanking marker loci. The frequency of $\mathbf{C}$ in Romanov ewes was assumed to be 0 , and genotypes of the Dorset 


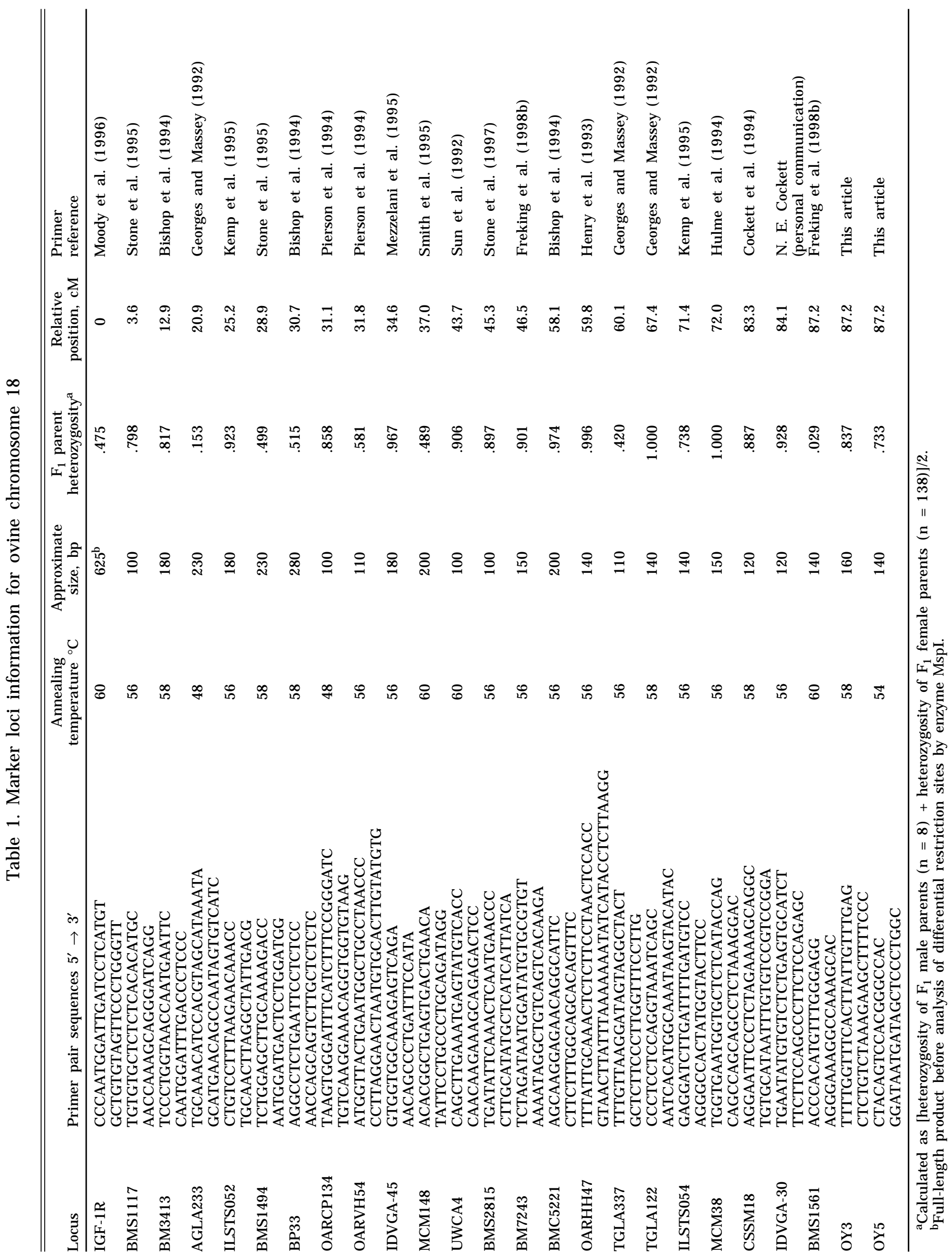


rams at the CLPG locus were heterozygous (frequency of $\mathbf{C}=.5$ ). The CHROMPIC output from the linkage analysis established the grandparental source (Dorset or Romanov) of alleles at the marker loci for the $F_{2}$ individuals. The conditional probability of an $F_{2}$ lamb's chromosome carrying $\mathbf{C}$ is the product of the probabilities that the $F_{1}$ parent inherited this allele from a Dorset ram and that same allele was subsequently inherited by the $F_{2}$ individual.

Probabilities of $F_{1}$ sires being heterozygous carriers of $\mathbf{C}$ were based on progeny test information. Seven of eight $F_{1}$ sires were assigned probabilities of unity of being heterozygous carriers. The remaining sire was given a probability of null based on 41 progeny all of normal phenotype and output from the linkage analysis, which indicated that this sire was in opposite phase with respect to the telomeric region of its paternal chromosome 18 compared to a paternal halfsib $F_{1}$ sire shown to be a carrier. Probabilities that $F_{1}$ dams were heterozygous carriers of $\mathbf{C}$ were calculated from the flanking genotypic information at each 1-cM position on the linkage group. The conditional probability of an $\mathrm{F}_{1}$ ewe's paternal chromosome carrying $\mathbf{C}$ is the product of probabilities that the Dorset sire inherited this allele from its own sire ( $\mathrm{P}=$ 1 ) and that the same allele was subsequently inherited by the $F_{1}$ ewe. This latter probability varies dependent on the presence or absence (indicating a crossover event) of paternal grandsire alleles flanking each position.

Probabilities that maternal and paternal chromosomes carried $\mathbf{C}$ were then used to calculate $\mathbf{C C}, \mathbf{C N}$, NC, and NN CLPG genotypic probabilities for each $F_{2}$ lamb, where $\mathbf{C}$ represents the mutant CLPG allele, $\mathbf{N}$ represents the normal allele(s), and the paternal allele of the genotype is listed first. For example, at position $86 \mathrm{cM}$, one lamb had probabilities of .0003, $.9995, .0000$, and .0002 for CC, CN, NC, and NN genotypes, respectively. Genotypic probabilities must sum to one within animal, creating a dependency.

\section{Statistical Analyses}

Based on empirical distributions, four traits that discriminated between callipyge and normal phenotypes were analyzed to position CLPG and to evaluate different models of gene action. The regression of Ioineye area on carcass weight was used to describe muscle size. An objective measurement of carcass shape was rump width regressed on carcass length, whereas a subjective assessment of carcass shape was leg muscling score regressed on carcass weight. The regression of carcass fat-free lean (carcass water plus carcass protein) on carcass fat provided a comparison of carcass components.

Traits were analyzed using a statistical model that included effects of year, sex, and sire to partially account for environmental and polygenic effects.
Regressions on CC, CN, NC, and NN probabilities ( NN effect was set to zero to remove the dependency) and genotype-specific second-order polynomials of appropriate covariates (described above) were also estimated. A single contrast involving CLPG genotypic effects provided a 9-df F-test (341 residual df) to evaluate significance of the full genotypic model. Analyses of traits were conducted at 1-cM intervals starting at the most centromeric marker and extending $20 \mathrm{cM}$ beyond the most telomeric marker. The Fstatistic from each analysis was plotted against the position. The position that maximized the F-statistic for a given trait was taken as the position of the CLPG locus.

After positioning the CLPG locus for each trait, different models of gene action were evaluated to partition the $9 \mathrm{df}$ associated with the full genotypic model. A set of three orthogonal contrasts ( $3 \mathrm{df}$ per contrast) of genotypic regressions and genotype specific linear and quadratic polynomial effects was developed. Contrasts of $\mathbf{C C}, \mathbf{C N}, \mathbf{N C}$, and $\mathbf{N N}$ effects defined traditional additive $(1,0,0$, and -1$)$, dominance $(-1,1,1$, and -1$)$, and reciprocal heterozygote $(0,1,-1$, and 0$)$ models of gene action, respectively. If the reciprocal heterozygote contrast was significant, the dominance contrast was misleading because the effect of one heterozygous genotype was underestimated and the other heterozygous genotype was overestimated. Under this situation, a second set of orthogonal contrasts was derived to include the polar overdominance hypothesis of Cockett et al. (1996). Three orthogonal contrasts of CC, CN, $\mathbf{N C}$, and $\mathbf{N} \mathbf{N}$ effects defined additive $(1,0,0$, and -1$)$, maternal dominance $(-1,0,2$, and -1$)$, and paternally derived polar overdominance $(-1,3,-1$, and -1$)$ models of gene action, respectively.

\section{Results}

\section{Ovine Chromosome 18 Map Development}

A linkage group of 25 loci flanking $87.2 \mathrm{cM}$ of ovine chromosome 18 was constructed. Relative genetic distances arranged from the most centromeric to the most telomeric are presented in Table 1 . Seven microsatellite loci (BMS1117, AGLA233, MCM 148, ILSTS054, IDVGA-30, OY3, and OY5) and the PCRRFLP for IGF-1R are new linkage assignments for ovine chromosome 18 compared to the most recent sheep linkage map (de Gortari et al., 1998). There were no discrepancies in locus order, and there was remarkable conservation of interval distances for the 16 markers in common with the homologous bovine chromosome 21 linkage group (Kappes et al., 1997). In contrast, the interval of $37.5 \mathrm{cM}$ between TGLA122 and IDVGA-30 of Cockett et al. (1996) is more than twice the distance reported herein $(16.7 \mathrm{cM})$. Like- 
Table 2. Summary of CLPG position analyses

\begin{tabular}{|c|c|c|c|c|c|c|c|c|}
\hline \multirow[b]{2}{*}{$\begin{array}{l}\text { Dependent } \\
\text { variable }\end{array}$} & \multirow[b]{2}{*}{ Covariate } & \multicolumn{5}{|c|}{ Full genotypic model } & \multicolumn{2}{|c|}{ Parsimonious model } \\
\hline & & $\begin{array}{l}\text { Position, } \\
\text { CM }\end{array}$ & $\begin{array}{l}\text { Maximum } \\
\text { F-test }\end{array}$ & Additive $^{b}$ & $\begin{array}{c}\text { Maternal } \\
\text { dominance }\end{array}$ & $\begin{array}{c}\text { Polar } \\
\text { overdominance }^{b}\end{array}$ & $\begin{array}{l}\text { Position, } \\
\text { CM }\end{array}$ & $\begin{array}{c}\text { Polar } \\
\text { overdominance }\end{array}$ \\
\hline Loin-eye area & Carcass weight & 87 & 62.1 & .50 & 1.97 & 164.41 & 91 & 183.0 \\
\hline Rump width & Carcass length & 86 & 38.3 & 2.13 & 1.57 & 110.66 & 86 & 106.6 \\
\hline Leg score & Carcass weight & 86 & 136.4 & 1.42 & .86 & 371.78 & 86 & 407.4 \\
\hline \multirow{2}{*}{$\begin{array}{l}\text { Carcass } \\
\text { fat-free lean }\end{array}$} & & & & & & & & \\
\hline & Carcass fat & 87 & 52.4 & .19 & 2.68 & 145.27 & 94 & 152.7 \\
\hline
\end{tabular}

a Maximum F-test ( $9 \mathrm{df}$ ) associated with full genotypic model (three genetic contrasts and interaction of each contrast with linear and quadratic covariate terms).

${ }^{\mathrm{b}} \mathrm{F}$-test ( $3 \mathrm{df}$ ) associated with additive, maternal dominance, or polar overdominance genetic contrasts and interactions with linear and quadratic covariate terms tested at the same relative position as the full genetic model.

'Maximum F-test ( $3 \mathrm{df}$ ) associated with polar overdominance effect and interactions with linear and quadratic covariate terms.

wise, de Gortari et al. (1998) estimated 97 cM between BM3413 and BMS1561, compared with 74.3 $\mathrm{CM}$ in the present research, a difference of $23 \%$. Differences in interval distances can be attributed to differences in family-specific recombination rates, genotypic data errors, and lack of precision of the estimated interval owing to sparse coinformative data. There were 1,082 possible informative meioses per marker for animals genotyped in this population. The mean number of informative meioses per marker on the linkage group was 708 (range 30 to 967) with similar contributions by males (54.3\%) and females $(45.7 \%)$. On average, genetic distance relationships between any two loci in this linkage group were determined from 482 coinformative meiotic events.

The distribution of recombination events per gamete transmitted by $\mathrm{F}_{1}$ parents to $\mathrm{F}_{2}$ lambs indicated that $37 \%$ of gametes exhibited no crossovers within the $87-\mathrm{cM}$ flanked region; $47 \%$ had a single crossover event; and only $16 \%$ had two, three, or four observed crossovers. Because gametes without crossovers do not help position the CLPG locus, only $63 \%$ of the gametes were informative for positioning. However, only $12.8 \%$ of the sheep were completely uninformative, in regard to CLPG position, at maternal and paternal chromosomes. This expected lack of recombination is the underlying genetic basis for imprecise positioning of an unknown locus, regardless of size of the effect in pedigrees extending only three generations. Occurrences of fortuitous recombination events close to the locus of interest have low probability in a single generation of segregation, and yet they are necessary to break up strong disequilibrium. The frequency of useful crossover events is primarily a function of experiment size.

Position and Gene Action of the Callipyge Locus

The most likely position of CLPG based on the full genotypic model ranged from 86 to $87 \mathrm{cM}$ for the four traits (Table 2). The maximum values for 9-df F-tests varied from 38.3 for rump width to $\mathbf{1 3 6 . 4}$ for leg score.
The 3-df contrast of reciprocal heterozygotes was significant for each trait (results not tabulated). Therefore, F-statistics for the three orthogonal contrasts derived to evaluate the polar overdominance model are presented for each trait. The additive and maternal dominance contrasts did not contribute significantly to the variation of any trait. A 3-df F-test would need to exceed a value of 8.0 to reach the genome-wide level of significance $(P=.05)$.

Because of the lack of evidence for differential effects among CC, NC, and NN genotypes, the additive and maternal dominance genetic effects were excluded to achieve a parsimonious model that included only the polar overdominance effect. The polar overdominance effect was estimated by regression on the difference between the $\mathbf{C N}$ probability and the pooled probability of $\mathbf{C C}, \mathbf{N C}$, and $\mathbf{N N}$ genotypes. The interaction of this effect with linear and quadratic covariate terms was also estimated. Analyses were again conducted at 1-cM intervals as described above. The profile of the polar overdominance F-test for leg score is presented in Figure 1. The position of CLPG based on the parsimonious model was less consistent among traits compared to results of the full genotypic model (Table 2). The 3-df F-test from the reduced model varied from 106.6 for rump width to 407.4 for leg score. These 3-df maximum F-values far exceed the genome-wide threshold value of 8.05 , which is the value of $\mathrm{F}$ that satisfies $\left[\left(\mathrm{C}+2 \rho \mathrm{g}_{\gamma_{1}} \mathrm{~F}\right) \mathrm{P}\right]=.05$ (Lander and Kruglyak, 1995), where $\mathrm{C}=27$ chromosomes, $\mathrm{g}=30$ morgans, $\rho=1$, and $\mathrm{P}$ is the probability that values from an $\mathrm{F}$-distribution with $\gamma_{1}=3$ numerator df and 347 denominator df exceed a value of $F$. The results of this experiment and the study conducted independently by Cockett et al. (1996) would represent a case of a locus that meets the Lander and Kruglyak (1995) criterion for confirmed linkage.

Recombination Evidence to Limit Flanked Region Containing the Callipyge Locus

Physical recombination evidence in rams with known CLPG genotype (progeny test) placed CLPG 


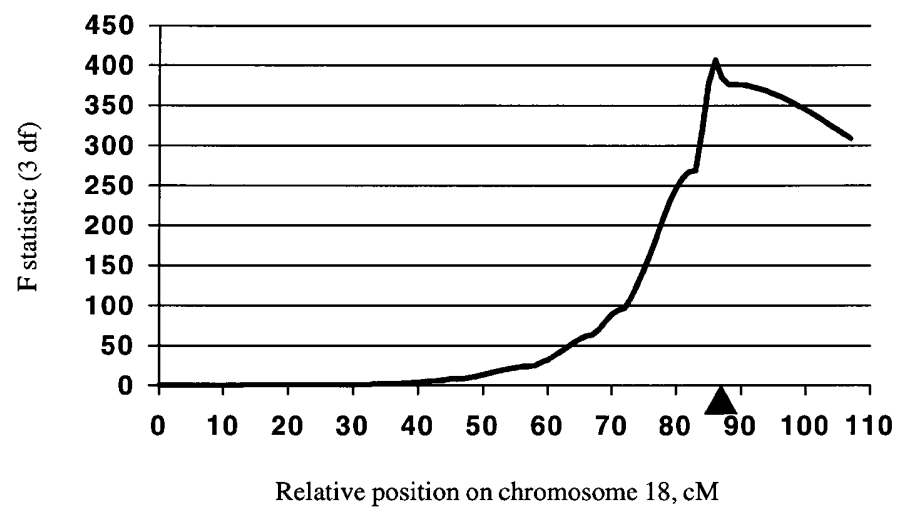

Figure 1. Profile of F-statistics for leg score regressed on carcass weight.

centromeric of the OY3-OY 5-BMS1561 haplotype. The single fortuitous recombination event occurred between CSSM 18 and the three-marker haplotype group and was detected on the paternally derived chromosome of one of the Dorset grandsires (9212042, Figure 2). A different haplotype of allele combinations from these four markers was in coupling phase with the mutant CLPG allele when transmitted to his progeny compared to the combination transmitted to progeny of a paternal half-sib Dorset ram (9212092) also used as a grandsire in this population. Thus, $F_{1}$ progeny from these two Dorset rams, with the same paternal grandparental (9012500) origin of the C allele, transmitted different marker alleles in coupling phase with the $\mathbf{C}$ allele at the OY3-OY5-BMS1561 loci but the same marker allele at the CSSM18 locus.

Recombination evidence also placed CLPG telomeric of CSSM 18. Three $F_{1}$ dams and four $F_{2}$ lambs expressed definitive callipyge phenotypes, implying that their CLPG genotypes were CN. Their maternal chromosomes were of Romanov origin. The centromeric regions of their paternal chromosomes through and including the CSSM18 locus were of Romanov origin in the four $F_{2}$ lambs and of paternal grandam origin (Dorset, $\mathbf{N}$ allele) in the three $\mathrm{F}_{1}$ dams. Recombinations in the interval between CSSM 18 and OY3-OY5-BMS1561 were detected on the paternal chromosomes, indicating that the telomeric region must contain the $\mathbf{C}$ allele transmitted by Dorset grandsires. These results jointly position CLPG telomeric of CSSM18 and centromeric of OY3-OY5BMS1561, which restricts the CLPG locus to a 3.9-CM interval between positions 83.3 and 87.2 in this linkage group. Individuals recombinant in this interval contribute to positional cloning experiments.

\section{Discussion}

A previous experiment determined linkage of the CLPG locus to ovine chromosome 18 (Cockett et al.,
1994). A genetic model of paternal polar overdominance was proposed (Cockett et al., 1996) to explain the relationship between callipyge phenotypes and genotypes. We confirm the hypothesis of paternal polar overdominance. The most probable position of the locus is within a 3.9-cM interval on chromosome 18 bounded by CSSM 18 and OY3-OY5-BMS1561. In contrast to Cockett et al. (1994), we found the most likely interval containing CLPG to be telomeric, rather than centromeric, of CSSM 18, which is at position $83.3 \mathrm{CM}$ in this linkage group. The OY3-OY5BMS1561 haplotype defines the telomeric boundary and represents the closest linkage of marker loci to the location of CLPG.

Regardless of the approach used, qualitative or quantitative, paternal polar overdominance was identified as the most likely genetic model. Reciprocal heterozygote genotypes expressed different phenotypes (polar), and the two homozygous genotypes produced similar, normal phenotypes (over-

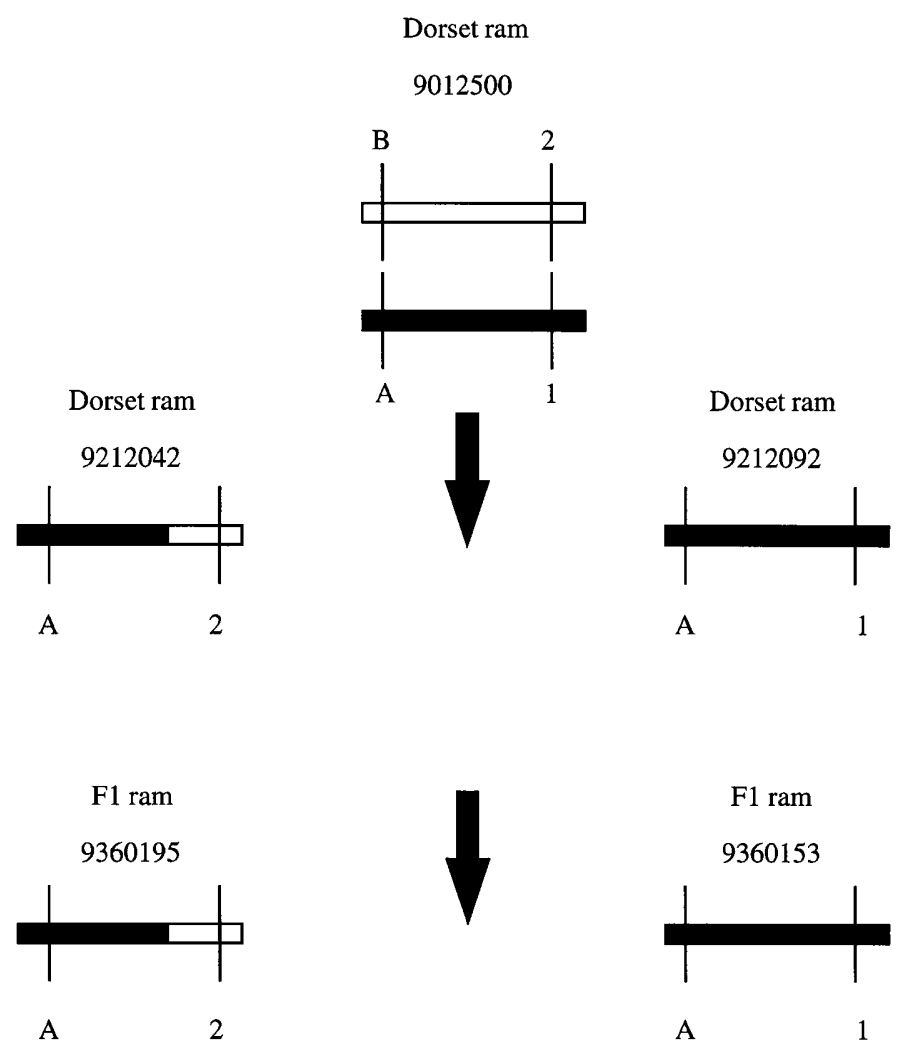

Figure 2. Transmission of paternally derived gametes showing a recombination event in the 3.9-cM interval for Dorset grandsire 9212042, which provides evidence that CLPG is centromeric of the right flanking haplotype. Solid bars represent gametes containing the mutant callipyge allele. All sires were known heterozygotes of the mutant callipyge allele based on progeny test. Left flanking marker (CSSM18) alleles are represented by letters, and the right flanking haplotype (OY3-OY5BMS1561) alleles by numbers. 
Table 3. Predicted percentages of offspring that show the callipyge phenotype for each possible mating combination ${ }^{\mathrm{a}}$

\begin{tabular}{|c|c|c|c|c|c|}
\hline & & \multicolumn{4}{|c|}{ Ram } \\
\hline \multicolumn{2}{|c|}{ Genotype/phenotype } & $\begin{array}{c}\text { CC } \\
\text { Normal }\end{array}$ & $\begin{array}{c}\text { CN } \\
\text { Callipyge }\end{array}$ & $\begin{array}{c}\text { NC } \\
\text { Normal }\end{array}$ & $\begin{array}{c}\text { NN } \\
\text { Normal }\end{array}$ \\
\hline \multicolumn{2}{|r|}{ Ewe } & & & & \\
\hline CC & Normal & 0 & 0 & 0 & 0 \\
\hline CN & Callipyge & 50 & 25 & 25 & 0 \\
\hline NC & Normal & 50 & 25 & 25 & 0 \\
\hline $\mathbf{N N}$ & Normal & 100 & 50 & 50 & 0 \\
\hline
\end{tabular}

${ }^{\text {a }} \mathbf{C}$ represents the mutant callipyge allele. $\mathbf{N}$ represents the wildtype normal allele(s).

dominance). Inferences concerning the actual expression of the different alleles for the gene(s) at the CLPG locus are speculative until it is positionally cloned and the variable alleles determined. Statements made in the literature about animals that express the CLPG gene refer to the expression of the phenotype rather than to unique gene expression on the molecular level. It is perhaps just as likely that the phenotype is caused by lack of normal gene expression or function at the CLPG locus. Evidence indicates that extreme phenotypic variants in musculature can be the result of loss of function, or disrupted function, of alleles at a single locus that act as regulators of normal muscle development ( $\mathrm{Fuji} i$ et al., 1991; Grobet et al., 1997; Kambadur et al., 1997; McPherron et al., 1997).

A genetic model built on the premise of a switch in the parent-specific origin expression pattern of an imprinted region and that null expression at the locus would cause the unique phenotype was suggested to explain the polar, preimplantation-embryo lethal phenotype known as the "DDK syndrome" in mice (Sapienza et al., 1992). Recent experiments led to the rejection of this hypothesis as the putative genetic model for the DDK syndrome (Pardo-Manuel de Villena et al., 1997). However, as discussed by Cockett et al. (1996), the "reverse imprinting" model could still be used to explain the segregation patterns for the callipyge phenotypes. The chromosome-specific methylation patterns, which are indicative of imprinted regions, can be tested when the locus is positionally cloned.

The unusual gene action of CLPG will require structured industry use of specific mating systems. Table 3 presents the expected percentage of progeny exhibiting the callipyge phenotype from all possible mating combinations in a two-allele (mutant CLPG vs wild type) single-locus model with paternal polar overdominance as the form of gene action. Only 6 of the 16 cells have been directly tested with reported experimental data. Experiments to completely evalu- ate these combinations are complicated because three genotypes ( CC, NC, and NN) have the same normal phenotype. Until the CLPG locus is cloned, inference of CLPG genotypes must be made using flanking markers and previously determined within-family phase information. The only mating combination expected to produce progeny that all express the callipyge phenotype is mating CC rams to NN ewes; both genotypes are associated with normal phenotypes. Cockett et al. (1996) reported exceptions to this expectation, but assumed no recombination between CLPG and their two most closely linked markers. Effects of the CLPG locus exceed any previously reported net breed effects on carcass composition (Freking et al., 1998a). Terminal sire mating systems with homozygous or heterozygous sires are most likely implementation scenarios. Specialized terminal sire lines can be developed in approximately $5 \mathrm{yr}$ by introgression of the $\mathbf{C}$ allele into genetic backgrounds of industry choice. Initial matings would require use of known CC, CN, or NC rams and visual evaluation of male progeny to identify carriers for the next generation of the backcross. In $4 \mathrm{yr}$ of backcross matings, turning one generation per year, heterozygous males and females ( CN) would exist that contain on average $15 / 16$ of the genetic background of choice. Inter se mating will produce $25 \%$ of progeny ( $12.5 \%$ mal es) as callipyge homozygotes (CC). The positional cloning of the CLPG locus becomes a relevant issue at this point because homozygous progeny need to be differentiated from two other genotypes ( NC and NN) with the same normal phenotype. Use of DNA-based assays to directly evaluate the allelic differences at the CLPG locus reduces costs associated with progeny testing a large number of rams and is more accurate than using flanking markers. When family phase information is known, currently available markers are useful to haplotype the locus with an acceptable error rate.

Use of the $\mathbf{C}$ allele would not be limited to mating schemes involving homozygous terminal sire systems. Heterozygous sires could be used in smaller flock mating systems in which progeny that express the callipyge phenotype are targeted for slaughter and noncarrier progeny are available for selection as replacement females. Any increase in frequency of the C allele in the ewe flock will decrease the percentage of progeny that expresses the hypertrophied phenotype.

Multiple-tier stratified breeding structures, such as exist in the United Kingdom, may be able to use different ram genotypes at different tiers. In the U.K. system, hill breeds are maintained in pure-breeding flocks and produce ewes for the upland sector. These ewes are crossed to longwool breed rams for the production of crossbred ewes subsequently used by the lowland sector in terminal sire matings. Heterozygous sires perhaps fit into this system as hill breed and 
longwool breed rams for the production of callipyge ewe and wether lambs for slaughter and normal phenotype ewes for breeding use by all three sectors. The half-bred ewe lambs that do not exhibit the callipyge phenotype could then be mated to homozygous CC rams in the terminal sire portion of this mating system to improve carcass composition in the lowland sector. The large effects of the $\mathbf{C}$ allele may justify use of heterozygous and(or) homozygous rams in a wide variety of breeds and production systems, but careful monitoring of allelic frequency in ewes is critical to maintain expected performance levels.

\section{Implications}

A resource flock of $362 F_{2}$ lambs provided the carcass and genotypic data necessary to refine the position of the callipyge (CLPG) locus to a 3.9-CM interval of chromosome 18. Efforts to positionally clone the gene responsible for this phenotype are greatly enhanced by this information. Individuals recombinant in this specific interval allow further refinement of map position. Gene action at the CLPG locus is characterized by unique muscle hypertrophy and low carcass fatness in heterozygous animals that inherited the allele from their sire. Other genotypes have a normal phenotype. Marker-based information could replace progeny-testing programs to provide sheep for mating systems that optimize production of the callipyge phenotype.

\section{Literature Cited}

Bishop, M. D., S. M. Kappes, J. W. Keele, R. T. Stone, S.L.F. Sunden, G. A. Hawkins, S. S. Toldo, R. Fries, M. D. Grosz, J . Yoo, and C. W. Beattie. 1994. A genetic linkage map for cattle. Genetics 136:619-639.

Broom, M. F., and D. F. Hill. 1994. Construction of a large-insert yeast artificial chromosome library from sheep DNA. Mamm. Genome 5:817-819.

Buetow, K. H. 1991. Influence of aberrant observations on highresolution linkage analysis outcomes. Am. J . Hum. Genet. 49: 985-994.

Cockett, N. E., S. P. J ackson, T. L. Shay, F. Farnir, S. Berghmans, G. D. Snowder, D. M. Nielsen, and M. Georges. 1996. Polar overdominance at the ovine callipyge locus. Science (Wash., DC) $273: 236-238$.

Cockett, N. E., S. P. J ackson, T. L. Shay, D. Nielsen, S. S. Moore, M. R. Steele, W. Barendse, R. D. Green, and M. Georges. 1994. Chromosomal localization of the callipyge gene in sheep (Ovis aries) using bovine DNA markers. Proc. Natl. Acad. Sci. USA 91:3019-3023.

de Gortari, M. J ., B. A. Freking, R. P. Cuthbertson, S. M. Kappes, J . W. Keele, R. T. Stone, K. A. Leymaster, K. G. Dodds, A. M. Crawford, and C. W. Beattie. 1998. A second generation linkage map of the sheep genome. Mamm. Genome 9:204-209.

de Gortari, M. J ., B. A. Freking, S. M. Kappes, K. A. Leymaster, A. M. Crawford, R. T. Stone, and C. W. Beattie. 1997. Extensive genomic conservation of cattle microsatellite heterozygosity in sheep. Anim. Genet. 28:274-290.
Freking, B. A., J. W. Keele, M. K. Nielsen, and K. A. Leymaster. 1998a. Evaluation of the ovine callipyge locus: II. Genotypic effects on growth, slaughter, and carcass traits. J. Anim. Sci. (In press).

Freking, B. A., R. T. Stone, M. J . de Gortari, and A. M. Crawford. 1998b. Chromosomal assignment by linkage of nineteen unassigned bovine microsatellites using ovine reference populations. Anim. Genet. (In press). 29:000-000.

Fujii, J ., K. Otsu, F. Zorzato, S. DeLeon, V. K. Khanna, J . E. Weiler, P. J. O'Brien, and D. H. MacLennan. 1991. Identification of a mutation in porcine ryanodine receptor associated with malignant hyperthermia. Science (Wash., DC) 253:448-451.

Georges, M., and J. Massey. 1992. Polymorphic DNA markers in bovidae (World Intellectual Property Org. Geneva). WO Publ. No. 92/13102.

Green, P. K., K. Falls, and S. Crooks. 1990. Documentation for CRIMAP, version 2.4. Washington University School of Medicine, St. Louis, MO.

Grobet, L., L.J .R. Martin, D. Poncelet, D. Pirottin, B. Brouwers, J . Riquet, A. Schoeberlein, S. Dunner, F. Menissier, J. Massabanda, R. Fries, R. Hanset, and M. Georges. 1997. A deletion in the bovine myostatin gene causes the double-muscled phenotype in cattle. Nat. Genet. 17:71-74.

Haley, C. S., S. A. Knott, and J . M. Elsen. 1994. Mapping quantitative trait loci in crosses between outbred lines using least squares. Genetics 136:1195-1207.

Henry, H. M., J . M. Penty, C. A. Pierson, and A. M. Crawford. 1993. Ovine microsatellites at the OARH H3, OARHH41, OARHH44, OARHH47, and OARHH64 loci. Anim. Genet. 24:223.

Hulme, D. J ., J . P. Silk, J . M. Redwin, W. Barendse, and K. J. Beh. 1994. Ten polymorphic ovine microsatellites. Anim. Genet. 25: 434-435.

J ackson, S. P., R. D. Green, and M. F. Miller. 1997. Phenotypic characterization of Rambouillet sheep expressing the Callipyge gene: I. Inheritance of the condition and production characteristics. J. Anim. Sci. 75:14-18.

Kambadur, R., M. Sharma, T.P.L. Smith, and J. J. Bass. 1997. Mutations in myostatin (GDF8) in double muscled Belgian Blue and Piedmontese cattle. Genome Res. 7:910-915.

Kappes, S. M., J. W. Keele, R. T. Stone, R. A. McGraw, T. S. Sonstegard, T.P.L. Smith, N. L. Lopez-Corrales, and C. W. Beattie. 1997. A second generation linkage map of the bovine genome. Genome Res. 7:235-249.

Keele, J. W., J. E. Wray, D. W. Behrens, G. A. Rohrer, S.L.F. Sunden, S. M. Kappes, M. D. Bishop, R. T. Stone, L. J . Alexander, and C. W. Beattie. 1994. A conceptual database model for genomic research. J . Computat. Biol. 1:65-76.

Kemp, S. J ., O. Hishida, J . Wambugu, A. Rink, M. L. Longeri, R. Z. Ma, Y. Da, H. A. Lewin, W. Barendse, and A. J. Teale. 1995. A panel of polymorphic bovine, ovine and caprine microsatellite markers. Anim. Genet. 26:299-306.

Lander, E. S., and L. Kruglyak. 1995. Genetic dissection of complex traits: Guidelines for interpreting and reporting linkage results. Nat. Genet. 11:241-247.

McPherron, A. C., A. M. Lawler, and S. J . Lee. 1997. Regulation of skeletal muscle mass in mice by a new TGF $-\beta$ superfamily member. Nature (L ond.) 387:83-90.

Mezzelani, A., Y. Zhang, L. Redaelli, B. Castiglioni, J . L. Williams, S. S. Toldo, G. Wigger, R. Fries, and L. Ferretti. 1995. Chromosomal localization and molecular characterization of 53 cosmid-derived bovine microsatellites. Mamm. Genome 6:629-635.

Moody, D. E., D. Pomp, and W. Barendse. 1996. Linkage mapping of the bovine insulin-like growth factor-1 receptor gene. Mamm. Genome 7:168-169.

Pardo-Manuel de Villena, F., A. K. Naumova, A. E. Verner, W. H. $\mathrm{J}$ in, and C. Sapienza. 1997. Confirmation of maternal transmission ratio distortion at $\mathrm{Om}$ and direct evidence that the maternal and paternal "DDK syndrome" genes are linked. Mamm. Genome 8:642-646. 
Pierson, C. A., A. J. Ede, and A. M. Crawford. 1994. Ovine microsatellite at the OARHH30, OARHH51, OARVH54, OARCP88, OARCP93, and OARCP134 loci. Anim. Genet. 25: 294-295.

Rohrer, G. A., D. W. Behrens, and J. W. Keele. 1994. A simplified procedure for entry of raw genotypic data. J . Computat. Biol. 1: 111-119.

Sapienza, C., J. Paquette, P. Pannunzio, S. Albrechtson, and K. Morgan. 1992. The polar-lethal Ovum mutant gene maps to the distal portion of mouse chromosome 11. Genetics 132:241-246.

Smith, A. J ., D. J . Hulme, J. P. Silk, J. M. Redwin, and K. J. Beh. 1995. Thirteen polymorphic ovine microsatellites. Anim. Genet. 26:277-278.
Sonstegard, T. S., S. M. Kappes, J. W. Keel, and T.P.L. Smith. 1998. Refinement of bovine chromosome 2 linkage map near the mh locus reveals rearrangements between the bovine and human genomes. Anim. Genet. 29. (I n press).

Stone, R. T., S. M. Kappes, J. W. Keele, and C. W. Beattie. 1997. Characterization of 109 bovine microsatellites. Anim. Genet. 28:5-9.

Stone, R. T., J . C. Pulido, G. M. Duyk, S. M. Kappes, J. W. Keele, and C. W. Beattie. 1995. A small-insert bovine genomic library highly enriched for microsatellite repeat sequences. Mamm. Genome 6:714-724.

Sun, H. S., M. R. Dentine, and B. W. Kirkpatrick. 1992. A polymorphic microsatellite (UWCA4) detected on bovine chromosome 21. Anim. Genet. 24:149. 